\title{
Alguns Apontamentos Sobre Racismo e Luta de Classes
}

Antônio Moreira da Silva Junior ${ }^{I}$

Wellington Amâncio da Silva ${ }^{I I}$

Resumo: O objetivo deste artigo é discutir as particularidades e possíveis articulações entre racismo e sociedade de classes enquanto processos construídos histórica, social e culturalmente. O texto traz informações sobre o racismo explanando suas origens, e justificando que o mesmo só tem razão de ser mediante a sociedade comercial. Levanta também a questão referente ao condicionamento que alguns segmentos são submetidos para concretizar sua adestração e dominação. Sugere que só através da consciência da sociedade de classes e seu fim poderemos tornar o mundo mais humano.

Palavras-chave: racismo; condicionamento; classe social; capitalismo

\section{Some Points About of The Racism and Classes Struggle}

Abstract: The purpose of this article is to discuss the circumstances and possible connections between racism and class society as historical processes built, socially and culturally. The text provides information on racism explaining its origins, and justifying that it has only one reason to be through a commercial society. It also raises the question about the conditioning that some segments are subjected to finish their "formation" and domination. Suggests that only through awareness of class society and its end we can make the world more human.

Keywords: racism; conditioning; social class; capitalism.

Artigo recebido em 13/12/2018 e aprovado em 29/12/2019. 
ANTÔNIO MOREIRA DA SILVA JUNIOR ; WELLINGTON AMÂNCIO DA SILVA

\title{
Introdução
}

\author{
O racismo desenvolveu-se no contexto criado pelo desenvolvimento da escravidão \\ sistêmica no 'Novo Mundo': a idéia de que os africanos eram (nas palavras de Hume) \\ naturalmente inferiores aos brancos justificou o ato de negar-lhes os direitos dos ingleses e \\ escravizá-los. \\ Callinicos
}

Ao analisar sucintamente a sociedade estratificada em classes, como também, a alienação ou o condicionamento a que são submetidas às classes ditas inferiores, pude também observar estas classes divididas em raças ${ }^{\mathrm{III}}$ em condições sociais concretas e veladas relacionada intencionalmente à ideia de raça. Esse modelo econômico propicia a manutenção do poder através de classes sociais e por meio do modelo economicista de raça. Além de legitimações e perpetuações, produz-se concomitantemente a isso matizes de racismos sedimentados em níveis econômicos e políticos característicos. Logo, entendemos o racismo como subproduto da sociedade de classes, perpetuando o logro por meio de discurso da democracia ${ }^{\mathrm{IV}}$ racial, pseudo-científico para legitimar e justificar ideologias.

\section{O Racismo Numa Perspectiva de Classe}

Certa feita, fui surpreendido ao acordar por minha mãe que me presenteou com uma revista em quadrinhos intitulada: "Homem Aranha versus Super Homem". Fiquei encantado com aquela epopéia mítica norte americana. Agora imagina uma criança de sete anos descendente de uma índia de origem Karuazúv ${ }^{\mathrm{V}}$, que inconscientemente é envolta num mundo de fantasias, onde corpos esculturais e mágicos fazem alusão a um mundo idealizado por algum artista pictórico, que junto a uma grande empresa dos quadrinhos, imprime na mente de milhões de crianças pelo mundo, um padrão estético da forma humana, oriunda da ideia grega de beleza.

\footnotetext{
"No transcorrer dos últimos 50 anos, os avanços acelerados da ciência têm gerado crescente brecha entre os conhecimentos do público e aquelas possuídas e utilizadas pelas elites dominantes. Graças à biologia, à neurobiologia e à psicologia aplicada, o "sistema" tem desfrutado de um conhecimento avançado do ser humano, tanto de forma física como psicológica. O sistema tem conseguido conhecer melhor o indivíduo comum do que ele mesmo conhece a si mesmo. Isto significa que, na maioria dos casos, o sistema exerce um controle maior e um grande poder sobre os indivíduos do que os indivíduos a si mesmos."VI
}

Essas mesmas crianças são submetidas, logo nas séries inicias da escola, a livros didáticos em que seus autores intitulam a Grécia como "o berço da civilização ocidental". Constroem-se ai os cidadãos civilizados, democráticos, ocidentais, repleto de imaginários planejados para funcionar na medida do conformismo, do simbólico elaborado para defender um modelo que não é seu, isto é, que é alugado a preço elevado.

Essa escola faz questão de ressaltar a forma de pensamento, o conhecimento da história, as ciências, a religião, a arte... esteticamente e eticamente, como idealizaram os gregos, onde apenas aí, na pólis, poderia haver cultura (Paidéia). Porém, não é que o 


\section{ANTÔNIO MOREIRA DA SILVA JUNIOR ; WELLINGTON AMÂNCIO DA SILVA}

público da educação em geral seja privado do acesso a essa cultura, mas que os discursos de inclusão, são na verdade legitimadores de simulacros de inserção não participativa e protagonista; apenas como mudança de comportamento, sem conhecimento profundo dos fatos:

[...] "Fazer com que o público seja incapaz de compreender as tecnologias e os métodos utilizados para seu controle e sua escravidão. "A qualidade da educação dada às classes sociais inferiores deve ser a mais pobre e medíocre possível, de forma que a distância da ignorância que paira entre as classes inferiores às classes sociais superiores seja e permaneça impossível para o alcance das classes inferiores." VII

Fato é que, com o mercantilismo europeu no século XV, ouve a necessidade de novas rotas comerciais ${ }^{\mathrm{VIII}}$, estes ideais de comércio foram trazidos para o "Novo Mundo" e, aqui, por assim dizer, esboçados, de forma unilateral - com o tempo, foi-se mudando o trato com a mão de obra tupiniquim disponível, segundo expedientes da história:

O século XV foi marcado por grandes mudanças ocasionadas pelas navegações européias. Os europeus conseguiram, ao criar rotas de acesso mais fácil através do oceano Atlântico, chegar à Ásia e a África Ocidental, além de estabelecer relação com territórios que até então não tinham contato com o mundo externo, como as Américas e a região Centro-Ocidental da África subsaariana. ${ }^{\mathrm{IX}}$

Destarte, sempre que os sujeitos que possuíam tecnologias "mais avançadas" se deparavam como sujeitos "menos" desenvolvidos, encontrava-se, in nuce, já o pretexto para submeter o outro às formas mais convenientes do logro. Assim, "do lado Atlântico para a África, a política expansionista dos europeus, sobretudo das monarquias ibéricas (Portugal e Espanha), tinha como principal intuito a exploração econômica de lucros imediatos, obtidos por meio do comércio."X Sua logística se efetivava pela submissão da mão de obra nativa.

Num país como o Brasil, onde a maioria da população é também composta por negros e índios, fica claro que há uma sobreposição de valores culturais, onde os aspectos econômicos e ideológicos são referenciais (nas entrelinhas do trato cotidiano e das propagandas televisiva, parece-nos haver uma aspiração à "branquificação" da população...), de modo que a história registra essa intenção quando sabemos que:

A elite no Brasil trouxe e subsidiou imigrantes europeus para "melhorar a qualidade" de sua força de trabalho e substituir os ex-escravos. Esta nova leva de mão-de-obra substituiu a população de ex-escravos africanos [...], ao mesmo tempo que agia como um "agente civilizador", embranquecendo o pool genético brasileiro. Esperava-se que os imigrantes brancos acabassem se mesclando à população nativa, de modo a diluir a grande população negra. ${ }^{\mathrm{XI}}$

Essa diversidade étnica é mais um problema do que uma solução em face das pretensões ideológicas que visa comandar classes e etnias a partir do absolutismo do Capital. Portanto, segundo Fernandes ${ }^{\mathrm{XII}}$, o discurso da democracia racial era apenas mais um discurso como eufemismo, visando abrandar retoricamente um quadro social perturbador, não anulando os estereótipos negativos do negro, pois: 


\section{ANTÔNIO MOREIRA DA SILVA JUNIOR ; WELLINGTON AMÂNCIO DA SILVA}

A estereotipação negativa na só impediu que o "branco" descobrisse esse aspecto da realidade, mas produziu algo pior: suscitou uma barreira invisível universal, que tolhia qualquer redefinição rápida da imagem do "negro", que facilitasse a transição do trabalho escravo para o trabalho livre e acelerasse pelo menos a proletarização do "homem de cor"XIII

Por outro lado, na perspectiva étnica, o referencial é destruído e substituído pela cultura hegemônica - a identidade é esquecida e muitas vezes ignorada pelos próprios pares, pois, o ideal de ser e de estar no mundo vai se constituindo através das lentes da cultura instituída. Portanto, identidade na modernidade torna-se instrumento de reprodução de modelos instituídos, e menos um referencial cultural e de pertencimento em que os sujeitos aproximam-se uns dos outro, num dado contexto étnico.

Consequentemente, os resquícios da senzala, naquilo que os senhores da casa grande determinavam, permanecem inculcados, e se reproduzem na forma de racismo silencioso, disfarçado. Sutilmente as práticas do racismo se utilizam de diversos mecanismos para condicionar e explorar as classes "economicamente inferiores"XIV que em sua maioria é constituída de seres humanos étnicos, sejam eles tradicionais, sejam eles urbanizados.

Segundo alguns estudiosos o conceito de racismo teria surgido ou se intensificado como subproduto da sociedade de classes. Pensamos que, no Brasil, o racismo foi sendo condicionados à dimensão da classe ${ }^{\mathrm{XV}}$, portanto, fica claro que subjugando o outro como raça inferior e lhe privando o acesso ao saber, torna-se fácil manipulá-lo para todo tipo de exploração, principalmente a comercial, sobretudo quando essas relações arbitrárias se dão num contexto de saber majoritário em oposição ao saber étnico.

\footnotetext{
O racismo moderno constitui-se, enquanto forma de ideologia de dominação de uma classe sobre outra, dentro das relações de produção da vida material. [...] O racismo é desta maneira, resultado de justificações e classificações ideológicas, com objetivos de subjugação e exploração da força de trabalho. Estas foram fundamentais para a solidificação do sistema capitalista no mundo. ${ }^{\mathrm{XVI}}$
}

Com base nos ideários de épocas remotas, como da Antiguidade Clássica ou da Idade Média, a ideia de superioridade racial estava, na verdade, atrelada à superioridade militar, científica e econômica de povos aparentemente mais favorecidos, como os egípcios, romanos e gregos, que se consideravam superiores aos demais, principalmente em relação aos conquistados, portanto a justificativa da escravidão e da dominação pela guerra se completaria com a justificativa bélica e violenta da retórica da vitória e da derrota.

Uma demostração clara do ápice destas ideias de superioridade se deu com o surgimento, no século $\mathrm{XX}$, do nazifascismo e o sonho da raça ariana como raça pura. $\mathrm{O}$ termo arianismo ou raça ariana teve seu auge do século XIX até a primeira metade do século XX. Segundo Marques ${ }^{\text {XVII }}$, figuras como Hitler impôs sua individualidade à coletividade, anulando a subjetividade de cada um: isso é totalitarismo, em outras palavras, a perda da diferença, da alteridade.

Alguns etnólogos do século XIX propuseram que todos os povos europeus de etnia branco-caucasiana eram descendentes do antigo povo ariano, e assim, justificando 


\section{ANTÔNIO MOREIRA DA SILVA JUNIOR ; WELLINGTON AMÂNCIO DA SILVA}

uma tradição, um resgate histórico, cultural e genético, como discurso facilmente aceitável no século XX, como discurso típico dessa época.

Naquela época, salientar, a desigualdade dos povos humanos saltava aos olhos dos europeus, que assumiam uma visão de colonizadores, verdadeiros responsáveis pelo controle do mundo "não-civilizado". Usavam os europeus ainda das mesmas ideias para justificar a dominação a que submetiam os outros povos, incluindo o Brasil.

[...] Embora biologicamente falando não existam raças humanas, os preconceitos que temos imcorporados continuam a ensinar-nos e avaliar a capacidade dos indivíduos e coletividades de acordo com a raça biologica na qual os classificamos. Na prática, sempre que associamos um comportamento a uma característica biológica de um indivíduo ou grupo estamos raciocinando de forma racista. Em outras palavras, mesmo desmentidos pelas ciências os preconceitos racistas permanecem vivos nas mentes de muitos indivíduos e coletividades. ${ }^{\text {XVIII }}$

Mesmo com o fim do nazismo a ideia de massificação, classificação e segregação dos povos permanesse, só que agora de uma forma disfarçada, mas ainda uma ideia totalitária ${ }^{\text {XIX }}$. No Brasil do século XXI podemos observar essa dominação e padronização com a desconstrução da cultura local segundo as demandas da cultura global.

O racismo tornou-se uma idelogia bem elaborada, sendo fruto da ciência europeia a serviço da dominação sobre a América, a Ásia e a África. E esta ideologia racista ganha força a partir da escravidão negra, adquirindo estatuto de teoria após a revolução industrial européia. ${ }^{\mathrm{XX}}$

Com a multipolarirazão economica do mundo pós guerra fria em detrimento de sua bipolarização, surgiram termos como: "globalização", "sociedade de consumo", "cultura de massa", "neoliberalismo". Homogenizar ou tornar padrão faz parte de uma política global de mercado, afinal, as empresas multinacionais querem e precisam estender seus negócios nos mais remotos mercados do planeta, com isso, o mundo se torna uma aldeia global, uma aldeia classista e racista, definida e pensada pela elite branca e economicamente dominante, classe esta que tem suas bases majoritariamente na Europa e América do Norte. Sobre isto Chomsky escreveu:

\footnotetext{
Para fazer com que se aceite uma medida inaceitável, basta aplicá-la gradativamente, a conta-gotas, por anos consecutivos. É dessa maneira que condições socioeconômicas radicalmente novas (neoliberalismo) foram impostas durante as décadas de 1980 e 1990: Estado mínimo, privatizações, precariedade, flexibilidade, desemprego em massa, salários que já não asseguram ingressos decentes, tantas mudanças que haveriam provocado uma revolução se tivessem sido aplicadas de uma só vez. ${ }^{\text {XI }}$
}

O pensador e ecritor Ariano Suassuna disse: "A universidade brasileira dá aulas de costa para o Brasil". Dar aulas de costa para o Brasil supõe abandonar nossa identidade, nosso regionalismo, para abraçar o importado. Um exemplo disto é o modelo escolar reprodutivista brasileiro que possui em sua grade currícular uma disciplina voltada ao estudo de uma língua estrangeira. Propositadamente é ensinada a língua que predomina no mercado internacional, com a pretenção justamente de inserir os alunos na globalização capitalista ${ }^{\mathrm{XII}}$. Tudo muito enriquecedor, porém, com 


\title{
ANTÔNIO MOREIRA DA SILVA JUNIOR ; WELLINGTON AMÂNCIO DA SILVA
}

objetivos pensados que levam a massificação e controle. Seria anacrônico ou utópico pensar a possibilidade de ensinarmos em nossas escolas o "tupi-guarani" ou o "banto".

Essa linguagem padronizada e exportada por países que possuem o controle industrial, tecnológico e econômico, já tem efeitos diretos no Brasil ${ }^{\mathrm{XXIII}}$.

É comum no dia a dia quando vamos a um restaurante, na loja de informática, ouvir música, negociar ou mesmo numa simples conversa informal com amigos, ouvirmos e falarmos expressões do tipo: fast food, hamburguer, hot dog, self-service, diet, ketchup, light, milk-shake, notebook, pen drive, web cam, mouse, homepage, gigabytes, backup, CD-ROM, chip, data-show, e-mail, enter, fax, modem, high definition, hardware, software, open, closed, play, exit, internet, media player, off-line, on-line, scanner, escape, shift, delete, baseball, basketball, fitness, game, golf, handball, motocross, mountain-bike, park, poker, show, skate, strip-tease, surf, tennis, topless, trailer, videotape, volleyball, video game, start, home theater, home office, baby doll, blazer, cotton, lycra, fashion, jeans, WC, blackout, checkup, tape, planet, black music, blues, CD, compact disc, country music, dance music, DJ, disc-jockey, flashback, funk, gospel, heavy metal, jazz, rap, rock, techno, best seller, credit-card, express, feedback, folder, Made in, market, marketing, outdoor, royalty, shopping center, slide, slogan, taxi, ticket, personal trainee, design, home banking, office boy, black power, gay, high society, serial killer, love, cowboy, freelance, top model, play ground. Essas e outras palavras já se incorporaram ao vocabulário do brasileiro como forma nítida da política de mercado estabelecida no mundo.

Vivemos hoje uma espécie de neocolonialismo, teoricamente livres, porém, ideologicamente dependentes. A engenharia economica social (a análise e a automatização de uma sociedade) ou "novo darwinismo social", pode ser caracterizada como a terceira guerra mundial, uma guerra silenciosa, levada a cabo utilizando armas biológicas subjectivas, "silenciosas".

\begin{abstract}
Assim, a qualidade da educação dada às classes inferiores deve ser da mais pobre, de maneira que a brecha da ignorância que isola as classes inferiores das classes superiores seja e permaneça incompreensível para as classes inferiores. Com tal incapacidade, mesmos os melhores elementos das classes inferiores têm pouca esperança de extirpar-se do lote que lhes foi atribuído na vida. Esta forma de escravatura é essencial para manter um verdadeiro nível de ordem social, paz e de tranqüilidade para as classes superiores dirigencial. XXIV
\end{abstract}

É comum ligarmos os televisores e vermos nos canais abertos assistidos pela população, um desfile de homens e mulheres ricos, esbeltas, nutridos, bem enquadrados, bem alinhados, loiros, esteticamente idênticos, a maquiagem, a fotografia, o cenário, o texto, a edição, o tema, a plástica, o melhor ângulo. Profissionais de altíssima competência são contratados para o espetáculo do condicionamento, tudo é muito bem pensado, muito sutil para o senso comum, porém muito elaborado e premeditado para os experts do assunto. A dosagem é dada aos poucos a massa, que inconscientemente vai abrindo concessões para seu adestramento, afinal, se faz mister a manutenção do poder.

"Os esforços da classe capitalista para estabelecer e manter divisões raciais é intensificado pela imprensa, o púlpito, os jornais cômicos, em resumo por todos os meios à disposição das classes dominantes. "XXV

Nos telejornais, os ancoras da apresentação como seus subalternos esbanjam um padrão de beleza eleitos por um segmento racista e elitista da sociedade, como também, as telenovelas que ditam modas, padrões de beleza e comportamento que nos 


\section{ANTÔNIO MOREIRA DA SILVA JUNIOR ; WELLINGTON AMÂNCIO DA SILVA}

remetem aos filmes e personagens hollywoodianos, personagens loiros de olhos azuis como num lindo conto de fadas. E sem falar dos programas de auditório: Xuxa, Angélica, Ana Hickmann, Ana Maria Braga, Eliana... Enfim, tudo tem que parecer perfeito, esteticamente perfeito, cada "close". Afinal, rostos expostos na grande mídia se tornam grandes celebridades, e o mito vende muito.

O negro e o índio pouco se vê representado, e quando aparece é de forma marginalizada ou estereotipada. É evidente que a "branquificação" do povo brasileiro também é cultural, política, social e representacional ${ }^{\mathrm{XVVI}}$, eliminando simbolicamente e/ou pelo esquecimento, silenciamento. Há toda uma origem histórica para tal afirmação. Por exemplo:

Diz-se que o racismo é tão antigo quanto à natureza humana, e em
conseqüência não poderia ser eliminado. Pelo contrário, o racismo tal como o
conhecemos hoje desenvolveu-se nos séculos XVII e XVIII para justificar o
uso sistemático do trabalho escravo africano nas grandes plantações do
'Novo Mundo' que foram fundamentais para o estabelecimento do
capitalismo enquanto sistema mundial. XXVII

No entanto com a mudança do paradigma econômico (muito menos do que a mudança do paradigma moral) com a Revolução Industrial houve uma mudança paradigmática do modo de produção capitalista, desencadeado na dimensão política, uma "abolição" muito característica no Brasil:

A Lei Áurea libertou cerca de 736 mil escravos, 5,6\% da população. Eles já não eram a mais importante força de trabalho nos principais centros. Por isso, não havia massa escrava lutando pela sua liberdade - o abolicionismo foi um debate político, não uma luta social. Acabaram-se os escravos; restaram os negros. XXVIII

Assim a TV aberta também é uma grande motivadora de preconceito e discriminação. O racismo surgiu e cresceu com o capitalismo e ajuda a sustentá-lo. A sua abolição depende, portanto de uma revolução socialista que rompa as estruturas materiais às quais estão vinculadas $[. . .]^{\mathrm{XXIX}}$. Enquanto isso, o racismo, me sentido amplo, isto é, em relação aquilo que é distinto da "identidade instituinte", parte de discursos e de práticas que visam à manutenção do egoísmo de grupo, da manutenção de um estatus quo de segregação, de casta, de núcleo beneficiado, da segregação dos não-iguais:

O racismo, portanto, formou-se como parte do processo através do qual o capitalismo tornou-se o sistema econômico e social dominante. As suas transformações posteriores estão ligadas às transformações do capitalismo. $^{\mathrm{XXX}}$

Enfim, o sistema capitalista além de marginalizar, tem tirado o caráter político dos movimentos e grupos sociais, (negros, índios, trabalhadores rurais...) diminuindo a sua resistência pela forma como esses grupos subjugados passaram a reivindicar em seus protestos muitos aspectos do "bem-estar" social consumista, anti-sustentável capitalista. 


\section{Considerações finais}

Tudo fica mais claro quando entendemos que a nossa sociedade está dividida em classes a partir de duas dimensões que condicionam uma a outra, a saber, a dimensão econômica e a dimensão étnica. Dentro dessa lógica de classe diversos grupos humanos são "subprodutos" da mesma, que de forma bizarra a burguesia alimenta a divisão dessas classes e raças, a partir de uma "ideologia civilizacional ocidental europeu" a qual seus pensadores etnoclassistas interpretam a partir do distanciamento geográfico, cultural, étnicos, econômico dele modelo que o Brasil ainda tenta evitar saber (mas, deseja ser), dificultando reflexões e ações condicio per quam da construção de alternativas autênticas para escapar de um sistema que oprime a todos. Cabe a esses segmentos tomar consciência de classe, que o racismo é viável, e dá lucro. Este entendimento levantará questionamentos que nos conduzirão a uma sociedade mais justa.

\section{Notas}

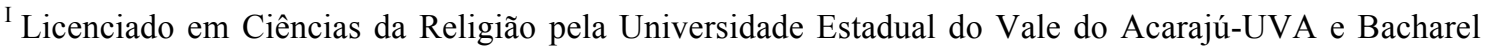
em Teologia pela Faculdade de Ciências, Educação e Teologia do Norte do Brasil-FACETEN. antoniojrprof@gmail.com

II Professor auxiliar na Universidade Federal de Alagoas - UFAL, Campus Sertão. Mestre em Ecologia Humana pelo Programa de Pós-Graduação em Ecologia Humana e Gestão Socioambiental UNEB/PPGEcoH. wellington.silva@cedu.ufal.br

III Diz-se raça no sentido contrário ao de etnia, isto é, de modo preconceituoso e unilateral.

IV Por si só, a democracia, onde ela nasce, na Grecia, evidenciava segregações de "classe" e de raça.Há de se perguntar quem era povo?

${ }^{V}$ Karuazú: comunidade indígena resultante do longo processo de migração experimentado por famílias Pankararu desde a extinção oficial do aldeamento de Brejo dos Padres (PE). Originou-se no século XIX de coletivos de identidade indígena genealógica e culturalmente ligados aos índios Pankararu (PE). Os Karuazú, constituíram-se a partir de uma das frentes de migração do aldeamento matriz pernambucano que foi responsável também pela constituição dos grupos Geripankó, Kalancó, koiupanka e katoquim, dispersos entre os municípios alagoanos de Pariconha, Água Branca e Inhapi, alto sertão do estado de Alagoas e a cerca de dois dias de caminhada de Brejo dos Padres (PE).

${ }^{V I}$ CHOMSKY, Noam. O lucro ou as pessoas: neoliberalismo e ordem global. $4^{\text {a }}$ Ed. Rio de Janeiro; Bertrand Brasil, 2004. p.50

${ }^{V I I}$ CHOMSKY, Noam. O lucro ou as pessoas: neoliberalismo e ordem global. $4^{\mathrm{a}}$ Ed. Rio de Janeiro; Bertrand Brasil, 2004. p.29

VIII As novas rotas comerciais determinariam as novas rotas espirituais, as novas rotas de desejos, de idealizações, projetos de vidas, estereótipos e engajamentos pessoais de um povo educado em face desta consciência comercial.

${ }^{\mathrm{IX}}$ MATTOS, Regiane Augusto de. História e cultura afro-brasileira. São Paulo: Contexto, 2007. p. 63

${ }^{X}$ MATTOS, Regiane Augusto de. História e cultura afro-brasileira. São Paulo: Contexto, 2007. p. 63

${ }^{X I}$ TELLES, Edward. Racismo à Brasileira. Uma nova perspectiva sociológica. Rio de Janeiro: Relume Dumará, Fundação Ford, 2003.p. 46).

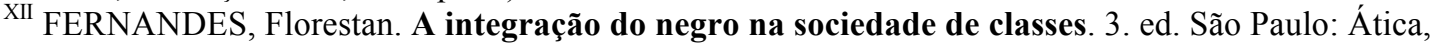
1978

XIII FERNANDES, Florestan. A integração do negro na sociedade de classes. 3. ed. São Paulo: Ática, 1978., p.141

XIV Certamente, numa perspectiva de manutenção pacífica da vida humana e ecológica, as economias étnicas sejam superiores ao modelo de economia vigente.
} 
XV CHAUÍ, Marilena. Manifestações ideológicas e autoritarismo brasileiro. Vol. 2. Belo Horizonte: Autêntica, 2013.; FERNANDES, Florestan. A integração do negro na sociedade de classes. 3. ed. São Paulo: Ática, 1978

${ }^{X V I}$ ROCHA, Luiz Carlos Paixão da. Políticas afirmativas e educação: a lei 10.639/2003 no contexto das políticas educacionais no Brasil Contemporâneo. Universidade Federal do Paraná, Curitiba, 2006.p. 7).

XVII MARQUES, Juracy. Ecologia da Alma. Petrolina: Gráfica Franciscana, 2012. p15

XVIII PRAXEDES apud ROCHA, Luiz Carlos Paixão da. Políticas afirmativas e educação: a lei 10.639/2003 no contexto das políticas educacionais no Brasil Contemporâneo. Universidade Federal do Paraná, Curitiba, 2006.p. 6

XIX ARENDT, Hannah. Origens do totalitarismo. São Paulo: Companhia das Letras, 1989

${ }^{\mathrm{XX}}$ SANT'ANA apud MUNANGA, Kabengele. Superando o racismo na escola. Brasília, SECAD, 2008. p. 45

${ }^{X X I}$ CHOMSKY, Noam. O lucro ou as pessoas: neoliberalismo e ordem global. $4^{\text {a }}$ Ed. Rio de Janeiro; Bertrand Brasil, 2004. p.67

XXII A globalização capitalista é, sobretudo, um processo “educacional”.

XXIII É interessante o caso da Língua Inglesa no Brasil: quase ninguém a aprende em escola pública. Parece-nos que ela é mais um processo de condicionamento e familiarização aos termos e nomes bonitinhos do inglês cotidiano.

XXIV CHOMSKY, Noam. O lucro ou as pessoas: neoliberalismo e ordem global. $4^{\text {a }}$ Ed. Rio de Janeiro; Bertrand Brasil, 2004. p.73.

XXV CALLINICOS, Alex. Capitalismo e racismo. São Paulo: Zahar,1993, p. 25

XXVI DA SILVA, Wellington Amâncio, O Sertão e seus sujeitos constituintes na Contemporaneidade (Comunicação/artigo) In. $1^{\circ}$ Encontro Nacional de História do Sertão - 2014a

XXVII CALLINICOS, Alex. Capitalismo e racismo. São Paulo: Zahar,1993, p. 8.

XXVIII CHIAVENATO, Julio José. O Negro no Brasil: da senzala a abolição. 1 ed. São Paulo: Moderna, 1999. p. 117

XXIX CALLINICOS, Alex. Capitalismo e racismo. São Paulo: Zahar,1993, p. 8.

${ }^{\text {XXX }}$ CALLINICOS, Alex. Capitalismo e racismo. São Paulo: Zahar,1993, p. 8.

\section{Referências}

ARENDT, Hannah. Origens do totalitarismo. São Paulo: Companhia das Letras, 1989

CALLINICOS, Alex. Capitalismo e racismo. São Paulo: Zahar, 2000.

CHAUÍ, Marilena. Manifestações ideológicas e autoritarismo brasileiro. Vol. 2. Belo Horizonte: Autêntica, 2013.

CHIAVENATO, Julio José. O Negro no Brasil: da senzala a abolição. 1 ed. São Paulo: Moderna, 1999.

CHOMSKY, Noam. O lucro ou as pessoas: neoliberalismo e ordem global. $4^{\text {a }} \mathrm{Ed}$. Rio de Janeiro; Bertrand Brasil, 2004.

FERNANDES, Florestan. A integração do negro na sociedade de classes. 3. ed. São Paulo: Ática, 1978.

GENOVESE, Eugene. Da rebelião à revolução. São Paulo: Global, 1983.

MARQUES, Juracy. Ecologia da Alma. Petrolina: Gráfica Franciscana, 2012. 
MATTOS, Regiane Augusto de. História e cultura afro-brasileira. São Paulo: Contexto, 2007.

MUNANGA, Kabengele. Superando o racismo na escola. Brasília, SECAD, 2008.

ROCHA, Luiz Carlos Paixão da. Políticas afirmativas e educação: a lei 10.639/2003 no contexto das políticas educacionais no Brasil Contemporâneo. Universidade Federal do Paraná, Curitiba, 2006.

DA SILVA, Wellington Amâncio, $O$ Sertão e seus sujeitos constituintes na Contemporaneidade (Comunicação/artigo) In. $1^{\mathrm{o}}$ Encontro Nacional de História do Sertão - 2014a

- A Intersubjetividade dos Processos Docentes - Análise do Discurso e teoria das Representações Sociais. In. Revista Ouricuri. Vol. 4, n. 1. mar./abr. 2014, p. 3. Disponível em <https://sites.google.com/a/nectas.org/revistaouricuri/> Acesso em $10 \mathrm{de}$ abril de 2014b.

A ordem do discurso no contexto docente e suas representações-uma nova proposta de reconstrução de sentidos. Revista Educação-UnG, v. 9, n. 1, p. 35-48, 2014c. ISSN 1980-6469.

Representations of Nature in Human Culture. American Journal of Human Ecology, v. 3, n. 1, p. 9-20, 2014d. ISSN 2167-9630.

TELLES, Edward. Racismo à Brasileira. Uma nova perspectiva sociológica. Rio de Janeiro: Relume Dumará, Fundação Ford, 2003. 